\title{
KORELACIJA RISK-PCI I SYNTAX SKORA RIZIKA KOD BOLESNIKA SA STEMI I NJIHOV PROGNOSTIČKI ZNAČAJ
}

\author{
Marko Vorkapić1 ${ }^{\text {, Gordana Krljanac }}{ }^{2}$ \\ ${ }^{1}$ Medicinski fakultet Univerziteta u Beogradu \\ ${ }^{2}$ Mentor; Urgentni centar Kliničkog centra Srbije
}

Sažetak

Uvod: STEMI je jedan od vodećih uzroka smrti u opštoj populaciji. Radi odabira optimalne terapije za STEMI bolesnike napravljeni su brojni klinički i anatomski skorovi rizika. U dosadašnjim studijama SYNTAX skor je korišćen kao anatomski skor rizika baziran na angiografskom nalazu dok je RISK-PCI prvenstveno klinički skor.

Cilj rada je da analizira postojanje i nivo korelacije između SYNTAX i RISK-PCI skora kao i da odredi u kojoj meri se možemo osloniti na njih u proceni prognoze i ishoda bolesti kod bolesnika sa STEMI.

Materijali i metode: Oba skora kao i klinički tok bolesti pratili smo kod konsekutivno lečenih bolesnika starijih od 18 godina koji su se prezentovali sa simptomima i znacima STEMI. Pacijenti su lečeni primarnom PCI i hospitalizovani u Koronarnoj jedinici (KJ) Klinike za kardiologiju KCS u periodu od avgusta 2014. do januara 2015. godine. Za određivanje SYNTAX skora koristili smo online softver: "SYNTAX score calculator", a za određivanje RISK-PCI skora kalkulator na sajtu Udruženja koronarnih jedinica Srbije. U obradi podataka koristili smo statistički program SPSS (IBM SPSS version 19).

Rezultati: Ukupno je u studiju uključeno 42 STEMI bolesnika. Prosečne godine starosti pacijenata su 57,4 \pm 10,6 godina, muškarci/žene 79/21\%. U našoj analizi dobili smo statistički visoko značajnu korelaciju SYNTAX i RISK-PCI skora $\mathrm{R}=0,641, \mathrm{p}=0,01$.

Zaključak: Između dva široko primenjena skora rizika kod bolesnika sa infarktom miokarda sa ST elevaciom (STEMI) postoji visoko značajna korelacija. To bi moglo da bude od velike važnosti, jer ukazuje na to da se dalja prognoza i ishod bolesnika sa STEMI može na adekvatan način predvideti na osnovu oba skora rizika.

Ključne reči: pPCI, STEMI, SYNTAX score, RISK-PCI score.
Abstract

Introduction: Myocardial infarction with ST elevation (STEMI) is a leading cause of death in the general population. In order to select the optimal therapy for STEMI patients many clinical and anatomic risk scores were calculated. In previous studies SYNTAX score was used as an anatomical risk score based on angiographic findings while RISK-PCI is primarily a clinical score.

The aim of this study is to analyze the existence and level of correlation between SYNTAX and RISK-PCI scores and to determine the extent to which we can rely on them in the assessment of prognosis and outcome of patients with STEMI.

Materials and Methods: Both scores and the clinical course of the disease were analysed in consecutive patients over 18 years of age that presented with symptoms and signs of STEMI. All patients received primary PCI and were hospitalized in the coronary care unit of the cardiology clinic, Clinical center of Serbia in the period of August 2014 - January 2015. The online software "SYNTAX score calculator" was used for determining the SYNTAX score and the United coronary care units of Serbia online software was used for the determination of RISK-PCI score. SPSS (IBM SPSS version 19) software was used for the statistical analysis of data.

Results: In total, the study included 42 STEMI patients. The median age of patients was $57.4 \pm 10.6$ years, male/female $79 / 21 \%$. In our analysis we obtained statistically significant correlation between SYNTAX and RISK$\mathrm{PCI}$ recent $\mathrm{R}=0.641, \mathrm{p}=0.01$.

Conclusion: We have found a highly significant correlation between two widely applied risk scores in patients with STEMI. This could be of great importance because it indicates that the further prognosis and outcome of patients with STEMI can be based on and adequately predicted by both risk scores.

Keywords: pPCI, STEMI, SYNTAX score, RISKPCI score. 


\section{Uvod}

Infarkt miokarda sa ST elevaciom (STEMI) je jedan od vodećih uzroka smrti u opštoj populaciji. U terapiji infarkta, poslednjih godina značajnu i rastuću ulogu zauzima perkutana koronarna intervencija (PCI). Uvođenje ovog terapijskog modaliteta višestruko je umanjilo mortalitet pacijenata, ali on nije bez svojih ograničenja. Alternativa za PCI jeste hirurška revaskularizacija miokarda (CABG): invazivna, kardiohirurška metoda koja ima veći morbiditet i mortalitet [1]. Ova metoda se smatra opravdanom kod trosudovne koronarne bolesti i bolesti glavnog stabla leve koronarne arterije prema aktuelnim preporukama za lečenje STEMI, ali brojni dodatni klinički i anatomski parametri utiču na odluku o primeni optimalnog načina lečenja [2]. Poslednjih godina pokazalo se da farmakoinvazivni pristup zbrinjavanja bolesnika (trombolitička terapija, a zatim PCI u vremenu od 3-24 h), u sredinama gde nije moguće odmah primeniti primarnu PCI može biti, ako ne bolje onda jednako dobro rešenje kao i primarna PCI u određenim grupama bolenika [3].

Postojanje više različitih pristupa u lečenju bolesnika sa STEMI iniciralo je potragu za reproducibilnim, objektivnim pokazateljima koji bi pomogli u donošenju odluke o zbrinjavanju i optimalnom lečenju. Istovremeno, napravljeni su i skorovi za stratifikaciju bolesnika prema riziku od komplikacija i smrti u zavisnosti od njihovih karakteristika (klinički pokazatelji) i stepena koronarne bolesti (anatomski pokazatelji). U potrazi za pravim pokazateljima stvoreno je više sistema za skorovanje. Razvojem sve sofisticiranijih metoda predikcije komplikacija $\mathrm{i}$ ishoda lečenja postalo je moguće predvideti i verovatnoću nastanka pojedinačnih komplikaciji prema tome prilagoditi farmakoterapiju pacijenta. Danas postoje brojni sistemi skorovanja i pravi izazov postaje odabrati onaj koji je u datoj situaciji superioran.

SYNTAX skor je anatomski skor primarno osmišljen radi stratifikacije pacijenata na one za koje je najbolja terapija PCI i one za koje je bolji izbor CABG. Ovaj skor bazira se na kvantitativnoj i kvalitativnoj analizi bolesti koronarnih arterija na osnovu 11 parametara koji uzimaju u obzir lokaciju i karakteristike lezije. Syntax studija, stožerna studija čiji je cilj bio evaluacija SYNTAX skora, ukazala je na mogućnost primene SYNTAX skora za procenu ukupnog rizika pacijenata sa STEMI [1]. Studije koje su ispitivale prediktivne mogućnosti SYNTAX skora i njegovih modifikacija ukazale su na mogućnost primene SYNTAX skora za evaluaciju mortaliteta u toku prve godine kod pacijenata sa bolešću glavnog stabla leve koronarne arterije lečenih PCI [4]. Osim toga pokazalo se da se možemo osoniti na SYNTAX skor kada je u pitanju predikcija ishoda kod pacijenata sa trosudovnom bolešću lečenih PCI [5]. RISK-PCI skor, sa druge strane, jeste klinički skor koji na osnovu 12 nezavisnih prediktora omogućava stratifikaciju tridesetodnevnog, ali i jednogodišnjeg rizika za pojavu ozbiljnih neželjenih kardiovaskularnih događaja (major adverse cardiovascular events-MACE) [6]. RISK-PCI skor i njegove modifikacije pokazale su se relevantnim u predikciji komplikovanih krvarenja i trombotske okluzije stenta posle PCI [7, 8].

Cilj rada je utvrđivanje korelacije SYNTAX i RISKPCI skora i određivanje u kojoj meri je moguce osloniti se na njih u proceni prognoze kod pacijenta $\mathrm{i}$ ishoda terapije STEMI.

\section{Materijali i metode}

Oba skora kao i klinički tok bolesti pratili smo kod konsekutivno lečenih bolesnika starijih od 18 godina koji su se prezentovali sa elektrokardiografskim i kliničkim znacima akutnog STEMI u okviru dvanaest sati od početka simptoma. Pacijenti su lečeni primarnom PCI i hospitalizovani u koronarnoj jedinici (KJ) Klinike za kardiologiju KCS u periodu od avgusta 2014. do januara 2015. godine.

Kriterijumi za isključenje su bili: odbijanje potpisivanja pristanka na invazivnu terapiju, aktivno ili nedavno krvarenje, poznati poremećaj koagulacije i krvarenja, poznata alergija na jodna kontrastna sredstva, alergija na klopidogrel ili aspirin.

SYNTAX skor obuhvata složenu analizu ekstenzivnosti, lokalizacije i morfologije promena na koronarnim arterijama čija se temeljna ilustracija može naći u tutorijalu na internet adresi http://www.syntaxscore.com/. Na navedenom sajtu nalazi se online softver: "SYNTAX score calculator" koji smo koristili za izračunavanje skora.

RISK-PCI skor obuhvata sledeće kriterijume: starost preko 75 godina, prethodni infarkt miokarda, kompletan AV blok, akutni blok desne grane, vrednost leukocita veću od $12 \times 10^{9} \mathrm{~g} / \mathrm{l}$, vrednost glukoze veću od $6,6 \mathrm{mmol} / \mathrm{l}$, klirens kreatinina (definisan u tri grupe u zavisnosti od visine vrednosti $(<60 \mathrm{ml} / \mathrm{min}$, od $60-89 \mathrm{ml} /$ $\mathrm{min}, \geq 90 \mathrm{ml} / \mathrm{min}$ ), ukupnu ejekcionu frakciju manju od $40 \%$, referentni dijametar manji ili jednak 2,5 mm, TIMI protok pre pPCI i TIMI protok posle pPCI. Pacijenti su dalje, prema RISK PCI skoru klasifikovani na one sa niskim $(0-2,5)$, srednjim $(3-4,5)$, visokim $(5-6,5)$ i veoma visokim $(\geq 7)$ rizikom.

RISK PCI skor smo određivali koristeći podatke iz istorija bolesti i uz pomoć online kalkulatora koji se nalazi na sajtu Udruženja koronarnih jedinica Srbije: http:// www.kjsrbije.rs/kalkulator.html

U analizi su praćeni glavni kardiovaskularni događaji u toku hospitalizacije (MACE) koji su definisani kao jedan od sledećih događaja: smrtni ishod, reinfarkt, 
maligni poremećaji ritma (VF ili VT), teži stepen srčane insuficijencije (Killip III I IV) i cerebrovaskularni insult (CVI).

U obradi podataka koristili smo statistički program SPSS (IBM SPSS version 19). Od meoda deskriptivne statistike koristili smo: mere centralne tendencije (aritmetička sredina, medijana i mod), mere varijabiliteta (interval varijacije, standardna devijacija i interkvartilni opseg) i relativne brojeve. Od metoda analitičke statistike koristili smo: a) metode identifikacije empirijskih raspodela, b) metode za procenu značajnosti razlike i to od parametarskih metoda: Studentov t-test i jednofaktorsku numeričku analizu varijanse, a od neparametarskih metoda: Hi-kvadrat za kategorijalne varijable. Koristili smo testove korelacije nezavisnih varijabli (Pearson korelacija). Prognostički značaj ispitivanih faktora koji utiču na pojavu intrahospitalnih kardiovaskularnih događaja analizirali smo univarijantnom logističkom regresionom analizom i ROC analizom. Kao statistički značajnu uzimali smo vrednost verovatnoće $<0.05$, a visoko značajnu $<0.01$.

Tabela 1. Baseline tabela karakteristika pacijenata

Pacijenti ( $\mathrm{N}=42)$

\section{Demografski podatci}

Godine starosti

Pol, m/ž (\%)

Body mass index

\section{Faktori rizika}

Hipertenzija, n (\%)

Pušenje, n (\%)

Porodično opterećenje, n (\%)

Dijabetes melitus n (\%)

Hiperlipidemija, n (\%)

Vreme od početka bola do dolaska u medicinsku ustanovu (sati)

\section{Komponente RISK-PCI skora}

Godine $>$ 75, n (\%)

Prethodni infarkt, n (\%)

Prednji infarkt, n (\%)

Kompletan AV blok, n (\%)

Akutni blok desne grane, n (\%)

Leukociti $>12.010-9 / \mathrm{L}, \mathrm{n}(\%)$

Glukoza * $\geq 6.6 \mathrm{mmol} / \mathrm{L}, \mathrm{n}(\%)$

Kreatinin klirens, $\mathrm{n} \geq 90 \mathrm{ml} \mathrm{u} \mathrm{min} / 60-89 \mathrm{ml} \mathrm{u} \mathrm{min} / \leq 60 \mathrm{ml} \mathrm{u} \mathrm{min}$

Ejekciona frakcija $<40 \%$, n $(\%)$

Referentni dijametar $\leq 2.5 \mathrm{~mm}, \mathrm{n}(\%)$

Pre-proceduralni TIMI protok 0, n (\%)

Post-proceduralni TIMI protok $<3$, n (\%)

$$
57,4 \pm 10,6
$$

$78 / 12$

$$
27,14 \pm 3,5
$$

$$
2,5 \pm 2,3
$$

$$
2(4,8)
$$

0

$17(40,5)$

$1(2,4)$

$2(4,8)$

$16(38)$

$18(43)$

$17 / 14 / 1$

$10(24)$

0

15 (36)

$4(10.6)$ 


\section{Rezultati}

Ukupno je u studiju uključeno 42 pacijenta. Prosečne godine starosti pacijenata su 57,4 \pm 10,6 godina. Od faktora rizika, prikazanih u tabeli 1 , nisu uočene statistički značajne razlike između muškaraca i žena ni u jednoj kategoriji, ali je značajan podatak da se $u$ ispitivanoj grupi nalazi $21.4 \%$ obolelih od dijabetesa.

$\mathrm{U}$ angiografskom nalazu, infarktnu levu descedentnu koronarnu arteriju imala su 19 muškaraca i ni jedna žena, dok je desna koronarna arterija bila infarktna arterija kod 7 muških i 7 ženskih pacijenata. Cirkumfleksna grana leve koronarne arterije bila je infarktna areterija kod jednog ženskog i tri muška pacijenta. Optuzna marginalna grana je bila infarktna kod jednog muškog pacijenta dok okluzija i tromboza dijagonalne grane ni u jednom slučaju nije registrovana. Trosudovna bolest se nalazila kod 1 ženskog i 7 muških pacijenata.

U našoj analizi dobili smo statistički visoko značajnu linearnu korelaciju dva posmatrana skora $\mathrm{R}=0,641, \mathrm{p}=0,01$, što je prikazano na grafikonu $\mathbf{1}$.
Univarijantnom logističkom regresionom analizom dobili smo sledeće rezultate: za RISK-PCI skor area under the curve je 0,507, a cut off za RISK-PCI skor je više od 2,5. Univarijantnom logističkom regresionom analizom je dobijeno da je RISK PCI značajan prediktor za pojavu MACE u toku intrahospitalnog praćenja: $\mathrm{OR}=0,707 ; 95 \%$ CI $0.561-0,892, \mathrm{p}=0,003$. Za SYNTAX skor, area under the curve je 0,414 , cut off vrednost za SINTAX skor je više od 15,5. Univarijantnom logističkom regresionom analizom je do- bijeno da je SINTAX skor značajan prediktor za pojavu MACE u toku intrahospitalnog praćenja: OR 0,$924 ; 95 \%$ CI $0,882-0,962$, $\mathrm{p}=0,001$.

\section{Diskusija}

Danas, $\mathrm{u}$ eri medicine zasnovane na dokazima i racionalne farmakoterapije, raste potreba za ra-cionalnim i reproducibilnim pokazateljima ishoda konzervativnih i invazivnih metoda terapije kao i pokazateljima koji će pomoći u opredeljenju za najbolju terapiju. Skoring sistemi

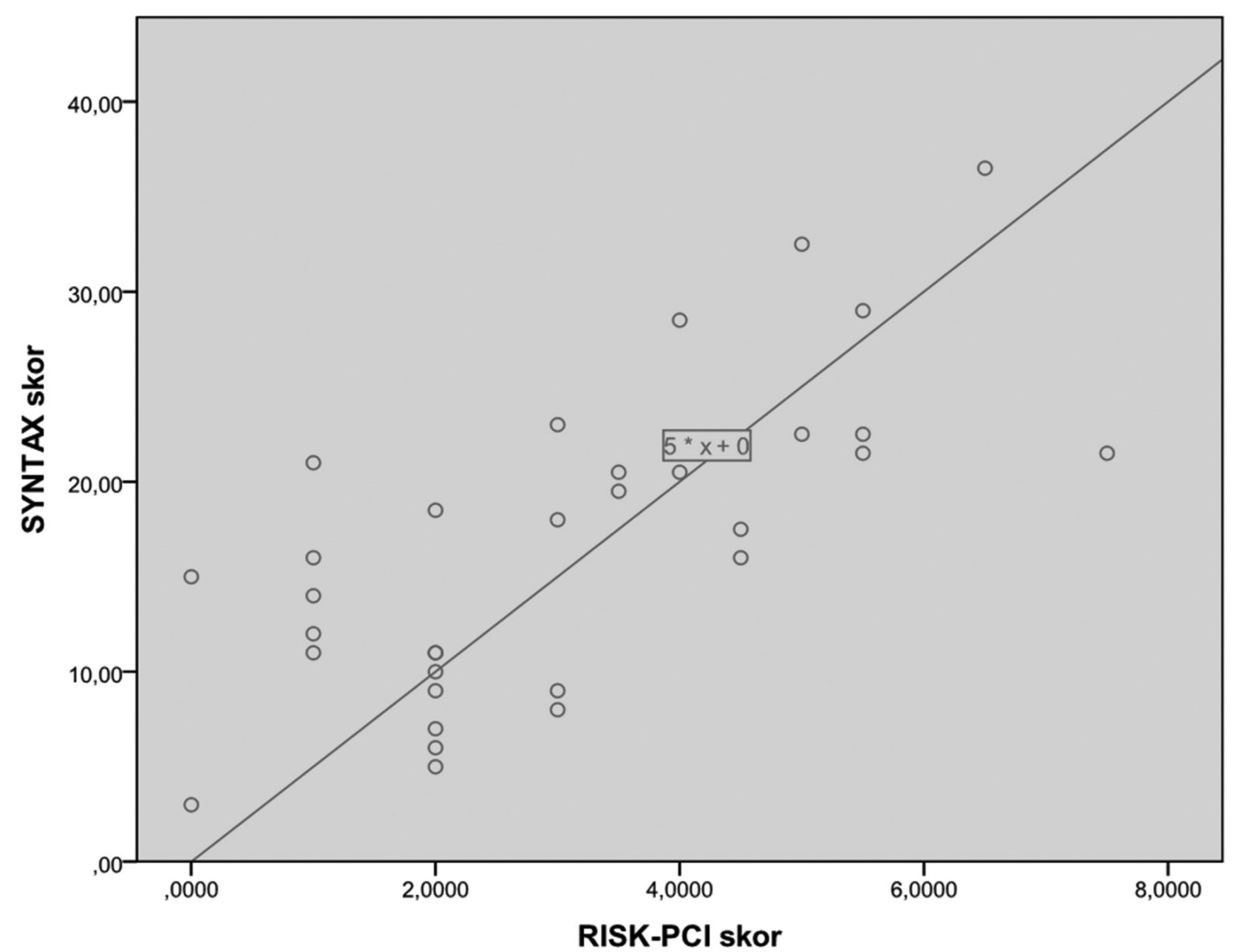

Grafikon 1. Korelacija SYNTAX skora I RISK-PCI skora 
osmišljeni u tu svrhu pristupaju problemu iz različitih perspektiva i samim tim imaju karakteristične prednosti, ali i nedostatke. SYNTAX skor, kao isključivo angiografski skor, temeljno opisuje i gradira koronarnu bolest, ali ne uključuje u jednačinu pojedinosti vezane za godine, funkcionalno stanje miokarda, biohemijske parametre, kao ni druge kliničke pokazatelje koronarne i pratećih bolesti. Osim toga, određivanje SYNTAX skora zahteva visok nivo stručnosti u analizi angiografskog nalaza i značajno iskustvo u korišćen-ju softvera za scoring [9]. Prediktivna vrednost SYNTAX- skora analizirana je u brojnim istraživanjima koja su uključivala različite populacije pacijenata i koje su potvrdile robustnost i reproducibilnost ovog skora [10]. RISK-PCI skor, kao predominantno klinički skor, ne posmatra temeljno bolest koronarnih arterija koja je u osnovi akutnog STEMI, ali uzima u obzir određene aspekte koronarne bolesti (TIMI protok pre i posle PCI, prisustvo/odsustvo infarkta prednjeg zida) i srčane funkcije (ejekciona frakcija) kao i prethodne bolesti (prethodni infarkt) [7]. Indikatori koji ulaze u izračunavanje RISK-PCI skora spadaju u standardnu obradu pacijenata hospitalizovanih u KJ tako da izračunavanje RISK-PCI skora ne zahteva dodatan trening, a s obzirom na to da su u pitanju dostupni parametri. Time je smanjena interob-zerverska varijabilnost koja predstavlja značajan problem pri izračunavanju SYNTAX skora [9]. RISK-PCI skor je noviji i samim tim manje istražen skor u odnosu na SYNTAX, ali je njegova vrednost ustanovljena na reprezentativnom uzorku pacijenata u RISK-PCI studiji, kao i iz nje proisteklim studi-jama [6].

Visoko statistički značajna korelacija koju smo dobili u rezultatima ove studije potvrđuje pred-iktivnu vrednost oba skora i omogućava uspostavljanje veze između njih. Takođe, korelacija dva skora rizika ukazuje na mogućnost da se različite perspektive sagledavanja ipak sustiču, te da postoji značajna veza kliničkih i anatomskih pokazatelja prognoze koronarne bolesti. Rezultati ove studije podstiču dalju težnju da se na većem uzorku temeljno sagledaju korelacije ovih skoring sistema.

\section{Zaključak}

Između dva primenjena skora rizika kod bolesnika sa STEMI postoji visoko značajna korelacija. To bi moglo da bude od velike važnosti, jer ukazuje da se već pri prijemu u koronarnu jedinicu, brzim izračunavanjem pre svega RISK-PCI skora koji je pretežno klinički pokazatelj, može sa sigurnošću predvideti i koronarografski nalaz izračunat komplikovanijim SINTAX skorom. Dalja prognoza i ishod bolesnika sa STEMI se na osnovu oba skora rizika može na adekvatan način predvideti.

\section{Reference}

1. Ong AT, S.P., Mohr FW, Morice MC, Kappetein AP, Holmes DR Jr et al, The SYNergy between percutaneous coronary intervention with TAXus and cardiac surgery (SYNTAX) study: design, rationale, and run-in phase. Am Heart J., 2006. 151: p. 1194-1204.

2. Serruys P, M.M., Kappetein A, et al., Percutaneous coronary intervention versus coronary-artery bypass grafting for severe coronary artery disease. N Engl J Med, 2009; 360: p. 961-72.

3. Janda, S.P. and N. Tan, Thrombolysis versus primary percutaneous coronary intervention for ST elevation myocardial infarctions at Chilliwack General Hospital. The Canadian Journal of Cardiology, 2009;25: p. e382-e384.

4. Chakravarty T, B.M., Naik H, et al., Predictive accuracy of syntax score for predicting long-term outcomes of unprotected left main coronary artery revascularization. Am J Cardiol., 2011;107: p. 360-366.

5. Valgimigli M, S.P., Tsuchida K, Vaina S, Morel MA, van den Brand and M.e. al, Cyphering the complexity of coronary artery disease using the syntax score to predict clinical outcome in patients with three-vessel lumen obstruction undergoing percutaneous coronary intervention. Am J Cardiol, 2007;99: p. 1072-1089.

6. Mrdovic I., S.L., Krljanac G., Perunicic J., Asanin M., Lasica R., et al., Predicting 30-day major adverse cardiovascular events after primary percutaneous coronary intervention: The RISK-PCI score. Int J Cardiol, 2013;162: p. 220 - 227.

7. Mrdovic I, K.G., Savic L, Asanin M, Lasica R, Djuricic $\mathrm{N}$ et al., Simple risk algorithm to predict serious bleeding in patients with ST-segment elevation myocardial infarction undergoing primary percutaneous coronary intervention: RISK-PCI bleeding score. Circ J., 2013;77: p. 1719-27.

8. Mrdovic I, S.L., Lasica R, Krljanac G, Asanin M, Brdar N et al., Usefulness of the RISK-PCI score to predict stent thrombosis in patients treated with primary percutaneous coronary intervention for ST-segment elevation myocardial infarction: a substudy of the RISK-PCI trial. Heart Vessels, 2013;28: p. 424-33.

9. Metzler B, W.B.e.a., SYNTAX, STS and EuroSCORE How good are they for risk estimation in atherosclerotic heart disease? . Thrombosis and Haemostasis, 2012.

10. Wykrzykowska JJ, G.S., Girasis C, et al., Value of the syntax score for risk assessment in the all-comers population of the randomized multicenter LEADERS (limus eluted from a durable versus erodable stent coating) trial. J Am Coll Cardiol., 2010;56: p. 272-277. 